\title{
Delta/Notch-Like EGF-Related Receptor (DNER) is Expressed in Hair Cells and Neurons in the Developing and Adult Mouse Inner Ear
}

\author{
Biron H. Hartman ${ }^{1,2}$, Branden R. Nelson ${ }^{1}$, Thomas A. Reh ${ }^{1,2}$, \\ and Olivia Bermingham-McDonogh ${ }^{1,2,3}$ \\ ${ }^{1}$ Department of Biological Structure, University of Washington, 1959 NE Pacific St., Box 357420 Seattle, WA 98195, USA \\ ${ }^{2}$ Institute for Stem Cells and Regenerative Medicine, UW Medicine Research, 815 Mercer St., Seattle, WA 98109, USA \\ ${ }^{3}$ Virginia Merrill Bloedel Hearing Research Center, University of Washington, Seattle, WA 98195, USA
}

Received: 4 September 2009; Accepted: 1 December 2009; Online publication: 8 January 2010

\begin{abstract}
The Notch signaling pathway is known to play important roles in inner ear development. Previous studies have shown that the Notch1 receptor and ligands in the Delta and Jagged families are important for cellular differentiation and patterning of the organ of Corti. Delta/ notch-like epidermal growth factor (EGF)-related receptor (DNER) is a novel Notch ligand expressed in developing and adult CNS neurons known to promote maturation of glia through activation of Notch. Here we use in situ hybridization and an antibody against DNER to carry out expression studies of the mouse cochlea and vestibule. We find that DNER is expressed in spiral ganglion neuron cell bodies and peripheral processes during embryonic development of the cochlea and expression in these cells is maintained in adults. DNER becomes strongly expressed in auditory hair cells during postnatal maturation in the mouse cochlea and immunoreactivity for this protein is strong in hair cells and afferent and efferent peripheral nerve endings in the adult organ of Corti. In the vestibular system, we find that DNER is expressed in hair cells and vestibular ganglion neurons during development and in adults. To investigate whether DNER plays a functional role in the inner ear, perhaps similar to its described role in glial maturation, we examined cochleae of $D N E R-/-$ mice using immunohistochemical markers of mature glia and supporting cells as well as neurons and hair cells. We found no defects in expression of markers of supporting cells and glia or myelin, and no abnormalities in hair cells
\end{abstract}

Correspondence to: Olivia Bermingham-McDonogh · Department of Biological Structure - University of Washington - 1959 NE Pacific St., Box 357420 Seattle, WA 98195, USA. Telephone: +1-206-6164652; fax: +1-206-5431524; email: oliviab@u.washington.edu or neurons, suggesting that DNER plays a redundant role with other Notch ligands in cochlear development.

Keywords: cochlea, vestibular, development, maturation, Notch

\section{INTRODUCTION}

The Notch pathway is a key regulator in the development of many tissues, including the sensory epithelia of the inner ear. Notch1 is expressed in the developing sensory epithelia of the mammalian inner ear (Lewis et al. 1998, Lanford et al. 1999) and several ligands for the Notch1 receptor are also expressed in the developing organ of Corti. Jagged1 (Jag1) is expressed at E10.5 in the prosensory region of the otic vesicle and is restricted to supporting cells during later development and in adults (Lewis et al. 1998, Morrison et al. 1999, Kiernan et al. 2006, Oesterle et al. 2008). Delta-like 1 (Dll1), Dll3, and Jag2 are coexpressed in hair cells during embryonic development and become downregulated in the postnatal mouse cochlea (Lewis et al. 1998, Lanford et al. 1999, Morrison et al. 1999, Hartman et al. 2007). The downstream effectors of the Notch pathway, Hes1, Hes5, Hesr1, Hesr2, and Hesr3, are all expressed in the developing organ of Corti as well as the vestibular sensory epithelia (Zheng et al. 2000, Zine et al. 2001, Hayashi et al. 2008, Li et al. 2008a, b, Doetzlhofer et al. 2009, Hartman et al. 2009). Loss of function mutations in Jag2, Dll1, Hes1, or Hes5 all lead to the development of extra hair cells (Zine et al. 2000, Zine et al. 2001, Kiernan et al. 2005, Brooker et al. 2006), as does the conditional deletion of Notch1 (Kiernan et al. 2005) 

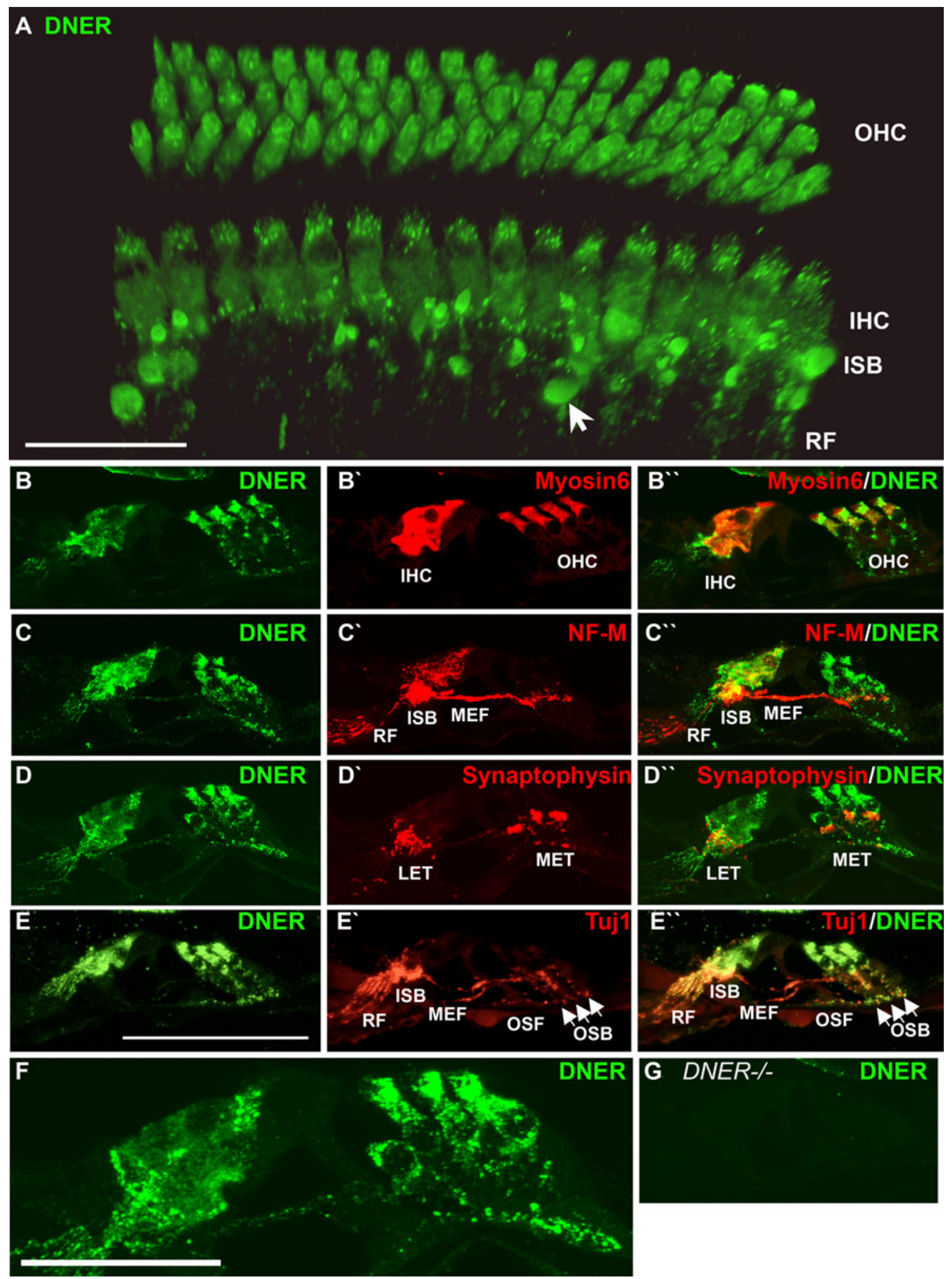

or inhibition of Notch signaling pharmacologically during late embryogenesis or neonatal periods (Takebayashi et al. 2007, Hayashi et al. 2008).

While these studies clearly demonstrate a critical role for the DSL ligands-Jag1, Jag2, and Dll1-in either the prosensory function of the Notch pathway or the lateral inhibitory pathway, we have recently found that a different type of Notch ligand, delta/ notch-like epidermal growth factor (EGF)-related receptor (DNER) is expressed during later stages of 
FIG. 1. DNER is expressed in hair cells and afferent and efferent peripheral neurites in the adult mouse cochlea. A A surface view of a 3D-rendered confocal z-series micrograph taken from an adult organ of Corti whole-mount preparation immunolabeled with anti-DNER (green). In this view, expression of DNER can be seen in the three rows of outer hair cells $(\mathrm{OHC})$, the row of inner hair cells $(I H C)$ in the region of the inner spiral bundle (ISB), below and medial to the inner hair cells. Within the ISB, DNER expression is strong in many presumptive efferent varicosities (arrowhead points to one example). B-G" Cryosections were double labeled for DNER and myosinVI, Neurofilament-M (NF-M), synaptophysin, or Tuj1. DNER was coexpressed in hair cells with myosinVI (B-B'). C-C" NF-M labeled the neurites of the inner spiral plexus, which are also strongly labeled with DNER, as well as the tunnel-crossing medial efferent fibers (MEF), which contained low levels of DNER. D-D" The olivocochlear lateral efferent terminals (LET) and medial efferent terminals (MET) were labeled specifically with anti-synaptophysin and were found to express DNER with a large degree of overlap. E-E' Anti-Tuj1 was used to label all of the afferent and efferent neurites in the organ of Corti to confirm the identity of the DNER-positive fibers and the brightness of the image was increased to ensure visualization of the fibers. In addition to the ISP and tunnel-crossing MEFs, the afferent type II outer spiral fibers (OSF, also referred to as basilar fibers) can be seen running laterally crossing the floor of the tunnel to the region below the outer hair cells where they join with other type II fibers to form the three outer spiral bundles $(O S B)$. Thus, DNER expression is enriched in all of the organ of Corti fiber populations particularly at the terminals. F Higher magnification view of DNER labeling in the organ of Corti from D. G DNER immunolabeling is absent in the organ of Corti of DNER-/- mice, confirming antibody specificity. Scale bar in $\mathbf{A}=50 \mu \mathrm{m}$. Scale bar in $\mathbf{E}=100 \mu \mathrm{m}$ and applies to panels, B-E" and $\mathbf{G}$. Scale bar in $\mathbf{F}=50 \mu \mathrm{m}$.

cochlear development. DNER was identified as a novel Notch ligand expressed in developing and adult central nervous system (CNS) neurons (Eiraku et al. 2002). DNER is a single-pass transmembrane protein containing ten epidermal growth factor-like repeats in the extracellular domain, similar to those of delta-like, Jagged, and Notch proteins (Eiraku et al. 2002, Nishizumi et al. 2002). In the cerebellum, where the role of DNER has been particularly well examined, this molecule promotes morphological and functional maturation of glia through intercellular activation of Notch signaling (Eiraku et al. 2005, Saito and Takeshima 2006, Tohgo et al. 2006). DNER binds to Notch1 at cell-cell contacts and stimulates Notch intracellular domain cleavage and CSL-dependent transcription in C2C12 myoblasts (Eiraku et al. 2005). In addition, DNER expressed in Purkinje neurons, induces Bergman glial process extension and maturation through gamma-secretase- and Deltex-dependent, CSLindependent (non-canonical) Notch signaling (Eiraku et al. 2005). Thus, DNER can act through both canonical and non-canonical Notch pathways.

In this study, we use immunolabeling and in situ hybridization to analyze the expression pattern of DNER in the mouse cochlea during development and in adults. We have found that DNER is expressed in auditory and vestibular hair cells during development of the sensory epithelial of the inner ear, partly overlapping in expression with other Notch ligands, $J a g 2$ and Dll1 and Dll3. In addition, DNER is expressed in the neurons and nerve fibers of the innervating spiral and vestibular ganglia, and the expression in both the hair cells and afferent neurons is maintained into adulthood. To determine whether DNER is required for supporting cell maturation, we examined cochleae of adult DNER-/- mice (Tohgo et al. 2006) for defects in expression of supporting cell markers.

\section{MATERIALS AND METHODS}

\section{Animals}

Wild-type and transgenic mice were housed in the Department of Comparative Medicine at the University of Washington (UWDCM). The Institutional Animal Care and Use Committee approved experimental methods and animal care procedures. DNER knockout mice were previously generated as described (Tohgo et al. 2006). DNER knockout mice were bred and housed at Kagoshima University Graduate School of Medical and Dental Sciences, 8-35-1 Sakuragaoka, Kagoshima-shi, Kagoshima 890-8544, Japan, under the care of Professor Hirohito Miura. DNER knockout mice were shipped live to the UWDCM and were euthanized for tissue collection upon arrival. DNER-/- and wild-type mice obtained by crossing heterozygous mutants were used for the analyses in this study. To determine the mouse genotypes, PCR analysis was carried out using the synthetic primers from the mouse genomic sequence. The primers used were EGFL1 (25 mer, CTAGG TAGCCAAGACACACCTCGAG), EGFL8 (25 mer, GAGACCTCACAGGCTGGGTCCCAGG), and Neo2 (25 mer, CATCGCCATGGGTCACGACGAGATC). Adult (21-30-day-old) mice were used for this study. A total of five $D N E R-/-$ mice, one DNER+/-, and three wild-type mice were collected for analysis. Mice were euthanized according to approved procedures: mice were killed by anesthesia with $\mathrm{CO}_{2}$ followed by cardiac perfusion with $4 \%$ paraformaldehyde (PFA).

\section{Fluorescent immunohistochemistry}

Embryos were collected from timed pregnant C57/BL6 mice and staged according to Kauffman (Kauffman 1992). For postnatal mice, postnatal day 0 (P0) was defined as the day of birth. Embryonic whole heads or P0-P5 half-heads, were fixed overnight in 4\% PFA in phosphate-buffered saline (PBS) at $4^{\circ} \mathrm{C}$. Adult cochleas were isolated from temporal bones, the stapes was removed from the oval window, a small opening was made in the apex, and cold 4\% PFA in PBS was perfused through the cochlea with a syringe. Perfused cochlea were then fixed overnight in $4 \%$ PFA in PBS at $4^{\circ} \mathrm{C}$, 

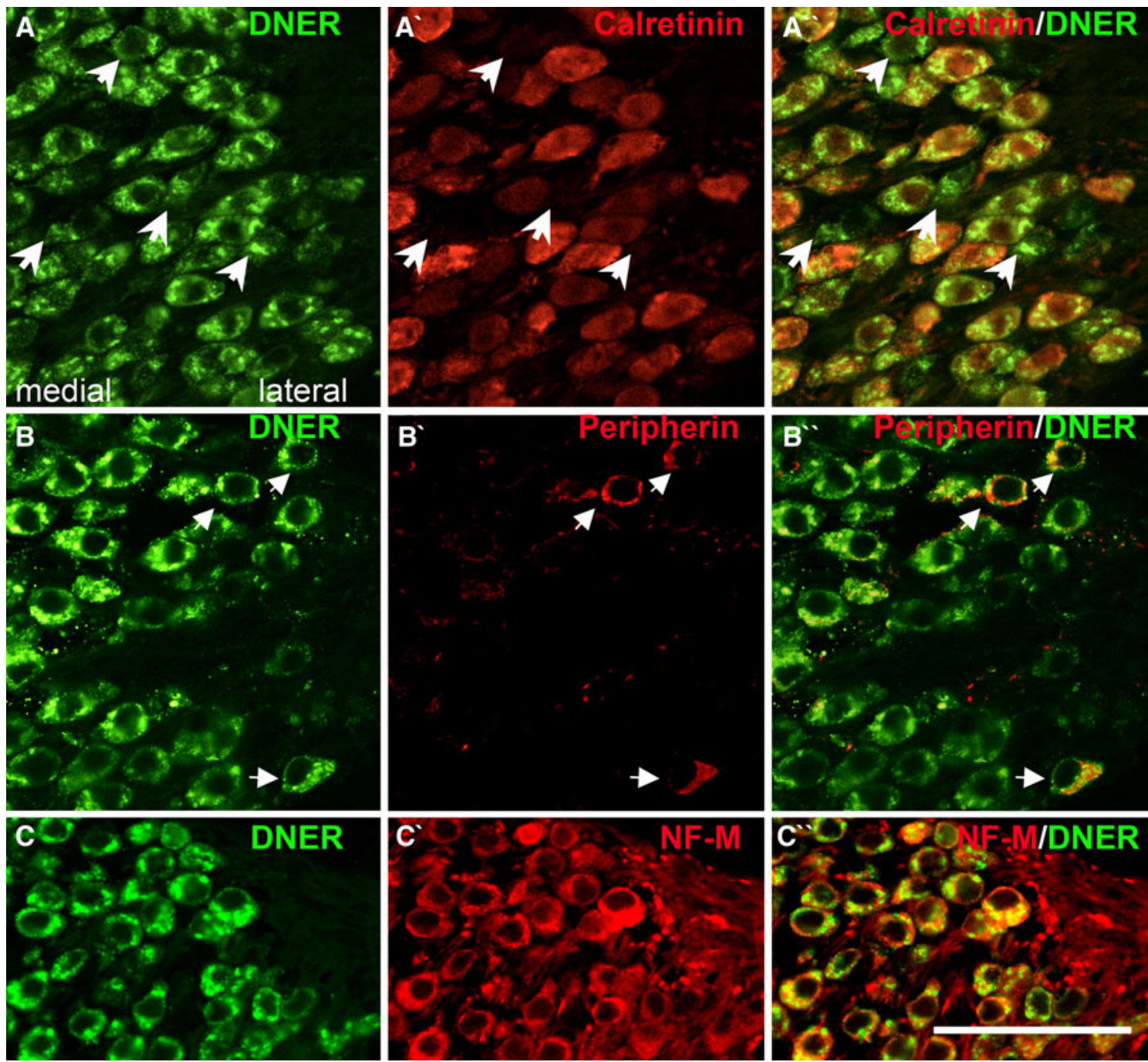

FIG. 2. DNER is expressed in types I and II spiral ganglion neuron somata in the adult cochlea. A-A" DNER (green) is expressed in the cell bodies of all calretinin-positive type I spiral ganglion cells (red). A small subset of DNER-positive spiral ganglion cells are negative for calretinin (arrowheads). B-B" DNER is expressed in the somata of all Peripherin- positive type II spiral ganglion cells (red, arrows). C-C" DNER expression in all spiral ganglion neuron cell bodies overlaps with that of NF-M (red), which labeled all spiral ganglion neuron cell bodies and projections. Scale bar $=100 \mu \mathrm{m}$.

$3 \times 10 \mathrm{~min}$, and incubated in species-specific fluorescentlabeled secondary antibodies AlexaFluor 488, 568, or $594 \mathrm{~nm}$ (1:500, Invitrogen). After immunostaining, tissues were coverslipped on slides in Fluoromount G (Southern Biotechnology, Birmingham, AL, USA). Images of most stained sections were acquired on a Zeiss Axioplan 2 microscope equipped with DIC optics and a Spot camera. Images of adult cochlea sections and whole-mount tissues were captured on a Zeiss LSM Pascal confocal microscope and processed using Improvision Volocity (3.0.2). Images were compiled with Adobe Photoshop 7.0.

\section{Antibodies}

Primary antibodies used were goat anti-DNER (R\&D Systems Cat\# AF2254) 1:100, Guinea pig anti-myosin- 
VIIa (S. Heller) 1:500, Rabbit anti-myosinVI (Proteus Biosciences) 1:1,000, mouse anti-Tuj1 (Covance) 1:500, rabbit anti-Neurofilament-M (145kD, Chemicon), rabbit anti-synaptophysin (Chemicon) 1:1,500, guinea pig anti-glutamate aspartate transporter (GLAST; Chemicon) 1:1,000, rabbit anti-glial fibrillary acidic protein (GFAP; DAKO) 1:1,000, and mouse anti-CNPase (Sigma) 1:200. Secondary antibodies used were goat anti-mouse Alexa 594, chicken antimouse 594, goat anti-rabbit Alexa 594, donkey antigoat 488, and goat anti-rabbit Alexa 488, all from Molecular Probes, and goat anti-guinea pig Cy3 from Chemicon.

\section{Paraffin in situ hybridization}

DIG-labeled antisense riboprobe was prepared for in situ hybridization for mouse DNER from cDNA clone MGC: 39059 (IMAGE: 5365190). In situ hybridization was performed as previously described (Nelson et al. 2004, Hayashi et al. 2007). Briefly, P5 and P7 halfheads (with brains removed), were fixed overnight at $4^{\circ} \mathrm{C}$ in modified Carnoy's solution $(60 \%$ ethanol, $11.1 \%$ formaldehyde ( $30 \%$ of $37 \%$ stock), $10 \%$ glacial acetic acid), dehydrated though an EtOH series, prepared for paraffin embedding, and sectioned at 6-8 $\mu \mathrm{m}$. Slides were baked overnight at $68^{\circ} \mathrm{C}$, dewaxed in Xylene, rinsed in $100 \% \mathrm{EtOH}$, and air dried at room temperature. Overnight hybridization and subsequent washes were carried out at $68^{\circ} \mathrm{C}$. Hybridized probe was detected using anti-Digoxygenin alkaline phosphatase conjugated antibody (1:2,000 dilution, Roche Biochemical, Indianapolis, IN, USA) and visualized with NBT/BCIP for a blue precipitate. After in situ hybridization, sections were post-fixed in 4\% PFA, rinsed in PBS, and mounted with Fluoromount G.

\section{RESULTS}

In the adult organ of Corti, DNER is expressed in hair cells and afferent and efferent peripheral neural processes and terminals

To analyze the expression of DNER in mature and developing inner ear, we used immunohistochemistry with an antibody raised against DNER. We verified that the labeling we found with this antibody in the cerebellum conformed to that already described in earlier publications (data not shown), and we also confirmed the expression in the inner ear using in situ hybridization in some cases. As an additional control for antibody specificity, the DNER expression patterns that we describe in this report were not present when we labeled sections from $D N E R-/-$ mice (see Figs. $1 G$ and 6 and 7 ).
DNER is expressed in auditory hair cells and peripheral neurites in the adult organ of Corti. Figure 1A shows a 3D-rendered confocal z-series micrograph of a whole-mount surface preparation of adult organ of Corti, DNER immunoreactivity was strong in both inner and outer hair cells as well in neurites associated with the inner hair cells, specifically the radial fibers and inner spiral bundle fibers (ISB, Fig. 1A). DNER expression was also apparent in presumptive efferent terminal varicosities (Fig. 1A, arrowhead marks one example), which were abundant in the region of the inner spiral bundle and radial fibers. Double-immunolabeling with anti-DNER and other markers of hair cells and neurite populations in sections of adult organ of Corti confirmed that hair cells and nerve fibers express DNER. DNER colocalized with myosinVI in inner and outer auditory hair cells (Fig. 1B-B"). The pattern of DNER immunolabeling in hair cells was punctate in the cytoplasm and mostly excluded from the nucleus. DNER was enriched in apical compartments of hair cells but was not present in hair cell bundles.

DNER is expressed in a punctate pattern in both afferent and efferent fibers and terminals in the adult organ of Corti, which were identified anatomically and by colabeling with specific markers (Fig. 1C-E"). Afferent fibers of type I and type II spiral ganglion neurons innervate inner hair cells and outer hair cells, respectively. The cochlear efferent neurons have their cell bodies in the superior olivary complex in the brainstem; the medial and lateral olivocochlear bundles innervate the outer hair cells and the radial fibers associated with the inner hair cells, respectively (Warr and Guinan 1979). In sections of adult organ of Corti, expression of DNER was most prominent in regions anatomically corresponding to the afferent radial fibers (terminals of type I spiral ganglia that synapse on inner hair cells), the inner spiral bundle (lateral efferents running under the inner hair cells) and the outer spiral bundles (fibers and terminals of type II spiral ganglia that synapse on outer hair cells; Fig. 1C, $\mathrm{D}$, and E). To confirm localization of DNER to specific fiber and terminal populations, we doublelabeled organ of Corti sections with anti-DNER and antibodies to Neurofilament (NF-M, Fig. 1C-C"), synaptophysin (Fig. 1D-D"), and Tuj1 ( $\beta$-III tubulin, Fig. $\left.1 \mathrm{E}-\mathrm{E}^{\prime \prime}\right)$. We have previously used the anti-Neurofilament-M antibody (Chemicon, $145 \mathrm{kD}$ NF-M) to label spiral ganglion cells and dendrites in the developing mouse cochlea (Hartman et al. 2007), and it has also been used to label both type I and type II spiral ganglion cells in the adult guinea pig (Corrales et al. 2006). In the adult mouse, the NF-M antibody labels spiral ganglion neuron cell bodies and many of their processes, as well as olivocochlear efferent nerve fibers, the inner spiral bundle and 
medial efferent tunnel-crossing fibers of the organ of Corti (Figs. $1 \mathrm{C}-\mathrm{C}^{\prime \prime}$ and $2 \mathrm{C}-\mathrm{C}^{\prime \prime}$ ). Synaptophysin is an intrinsic membrane protein of synaptic vesicles present specifically in the medial and lateral olivocochlear efferent nerve terminals (Fig. 1D-D'; GilLoyzaga and Pujol 1988, Knipper et al. 1995, Counter et al. 1997). The Tuj1 mouse monoclonal antibody (Covance) is highly reactive against the neuron specific $\beta$-III tubulin and labels the projections of all cochlear neurons in rats (Lallemend et al. 2007) and we found it also labels all of the projections in the adult mouse cochlea (Fig. 1E-E'). Close examination of double-labeled sections confirmed that DNER protein is found in all fiber populations labeled with NF-M and Tuj1 (Fig. 1C-C' and $\mathrm{E}-\mathrm{E}^{\prime \prime}$ ), with most intense labeling in the radial fibers, inner spiral bundle, and fibers below the outer hair cells, which include both type II afferent fibers and medial efferent terminals. DNER immunolabeling was frequently found throughout synaptophysin-labeled medial and lateral efferent terminals (Fig. 1D-D").

\section{DNER is expressed in both type I and type II spiral} ganglion neurons in the adult

We performed double-immunolabeling experiments with anti-DNER and three other distinct markers of spiral ganglion cell populations (Fig. 2), to evaluate which, if any, expressed DNER in the adult. We found that all spiral ganglion cell bodies were labeled with DNER in the adult mouse cochlea (Fig. 2A-C and $\mathrm{A}^{\prime \prime}-\mathrm{C}^{\prime \prime}$ ) and confirmed that DNER colocalized with

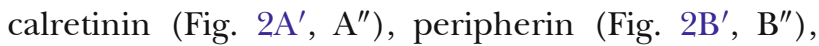

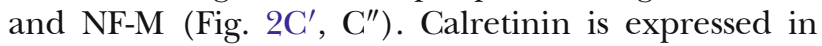
most type I spiral ganglion cells in rodents, but not in type II spiral ganglion cells (Dechesne et al. 1991, Dechesne et al. 1994, Koo et al. 2002). Consistently, we found that DNER is expressed in all calretininpositive cell bodies and most of the cells labeled with DNER were also labeled with calretinin. About onethird of the DNER-labeled cells were negative for calretinin (arrowheads point to several examples in Fig. 2A-A"). The DNER-positive but calretinin-negative spiral ganglion neurons were typically small and most were located in the lateral portions of the ganglia, many of which are likely type II spiral ganglion neurons. To confirm that DNER is expressed in type II spiral ganglion cells, we double-labeled sections with antibodies to DNER and peripherin (Fig. 2B-B"), which has been shown to be expressed specifically in type II spiral ganglion neurons in adult rodents (Hafidi et al. 1993, Hafidi 1998). DNER was expressed in all of the peripherin-labeled type II spiral ganglion cells, which made up a small subset of total spiral ganglion neurons and were typically found in the lateral portions of the ganglia. We also double-
FIG. 3. During embryonic development, DNER is expressed strongly in spiral ganglion neurons and initially at low levels in auditory hair cells, then becomes strongly expressed in auditory hair cells during postnatal development. A-E" A developmental series of cryosections of cochlear middle turns from E15.5 to P7 immunolabeled for DNER (red, all panels) and colabeled with either anti-Tuj1 (neurons, green $\mathbf{A}^{\prime \prime}$ and $\mathbf{C}^{\prime \prime}$ ) or transgenic Math1-GFP (hair cells, green, $\mathbf{B}^{\prime \prime}, \mathbf{D}^{\prime \prime}$, and $\left.\mathbf{E}^{\prime \prime}\right)$. The left column (A-E) shows low magnification views that include the spiral ganglia (sg) and the organ of Corti (oc), while the corresponding panels in the middle column (designated' and ") are high magnification single and mergedchannel views of the cochlear epithelium and the right column (designated "') shows higher magnification views of DNER immunoreactivity within the organ of Corti. During embryonic development (E15.5 A-A" and E17.5 B-B") DNER expression is strong in the spiral ganglion $(s g)$ cell bodies and less intense in their peripheral processes, which extend laterally to the developing organ of Corti (oc). Spiral ganglion neurons are double labeled with DNER and Tuj1 antibodies at E15.5 (green, $\mathbf{A}^{\prime}$ and $\mathbf{A}^{\prime \prime}$ ). DNER is expressed at low levels in auditory hair cells labeled with Math1-GFP at E17.5 (green, $\mathbf{B}^{\prime}$ and $\mathbf{B}^{\prime \prime}$ ). C- $\mathbf{E}^{\prime \prime}$ During postnatal development of the cochlea, DNER expression becomes intense in the peripheral neurites of the organ of Corti (colabeled with Tuj1 in $\mathbf{C}^{\prime}$ and $\mathbf{C}^{\prime \prime}$, and examples marked with upward pointing arrows in $\mathbf{A}^{\prime \prime \prime}-\mathbf{E}^{\prime \prime \prime}$ ), and with age becomes progressively more intense in hair cells (labeled with Math1-GFP in $\mathbf{D}^{\prime}-\mathbf{D}^{\prime \prime}$ and $\mathbf{E}^{\prime}-\mathbf{E}^{\prime \prime}$, and marked with downward pointing arrowheads in $\mathbf{A}^{\prime \prime \prime}-\mathbf{E}^{\prime \prime \prime}$ ) leading up to strong expression in hair cells at P7 (E-E"). The inset in E shows a section of P5 spiral ganglia probed with in situ hybridization for expression of DNER mRNA (blue), which, similar to antibody labeling, produced a signal in spiral ganglion neurons. Scale bar in $E=100 \mu \mathrm{m}$ and applies to the left column (A-E). Scale bar in $\mathbf{E}^{\prime \prime}=50 \mu \mathrm{m}$ and applies to the middle column $\left(\mathbf{A}^{\prime}-\mathbf{E}^{\prime \prime}\right)$. Scale bar in $\mathbf{E}^{\prime \prime \prime}=50 \mu \mathrm{m}$ and applies to the right column $\left(\mathbf{A}^{\prime \prime \prime}-\mathbf{E}^{\prime \prime \prime}\right)$.

labeled tissues with anti-DNER and rabbit anti-NF-M, which labels all spiral ganglion neuron cell bodies and many of their processes (Fig. 2C-C'; ; Corrales et al. 2006), confirming that DNER is expressed with NF-M in all adult spiral ganglion cell bodies.

DNER is expressed in spiral ganglion neurons and auditory hair cells during embryonic and postnatal development

We next carried out a series of developmental studies of DNER expression in the hair cells and neurons of the cochlea (Fig. 3). At E15.5, DNER is expressed strongly in the cell bodies of spiral ganglia neurons and at lower levels in their peripheral processes, which extend laterally to the developing organ of Corti (Fig. 3A-A"'). Expression of DNER was largely overlapping with that of Tuj1 in the spiral ganglion neurons and processes (Fig. 3A-A'"'). After E15.5, DNER continues to be expressed in spiral ganglion cell bodies and peripheral processes throughout embryonic and neonatal development, as shown at E17.5, P2, P4, and P7 (Fig. 3B, C, D, and E, respectively). To confirm DNER localization in 

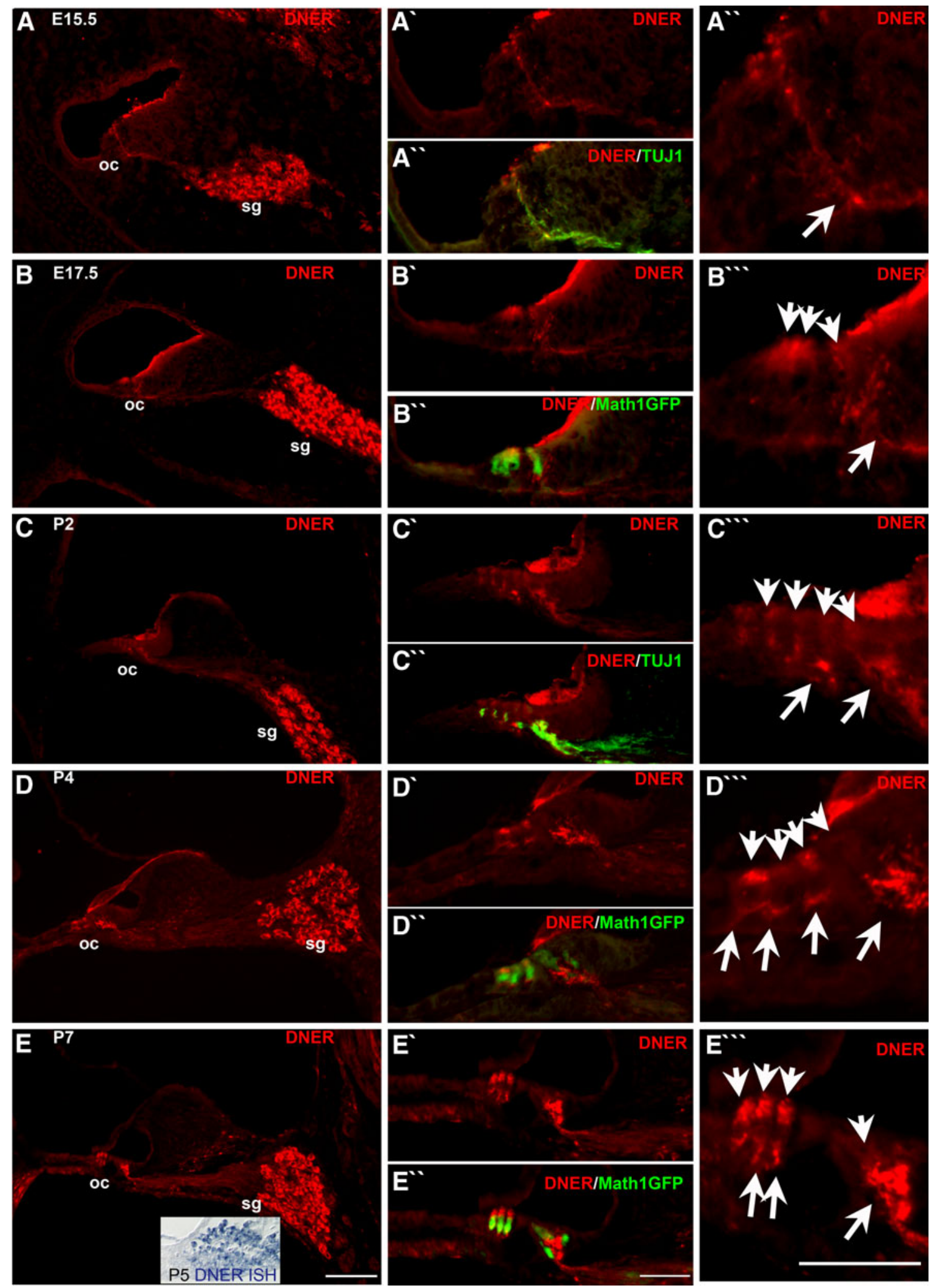

peripheral processes we colabeled with Tuj1 and found a high degree of overlap in the fibers approaching and within the organ of Corti, as shown here at E15.5 and P2 (Fig. $3 \mathrm{~A}^{\prime}-\mathrm{A}^{\prime \prime \prime}$ and $\mathrm{C}^{\prime}-\mathrm{C}^{\prime \prime \prime}$, respectively). We also performed in situ hybridization for DNER on sections of P5 inner ear and found expression in spiral ganglia neurons, consistent with the immunolabeling pattern (Fig. 3E, inset). 

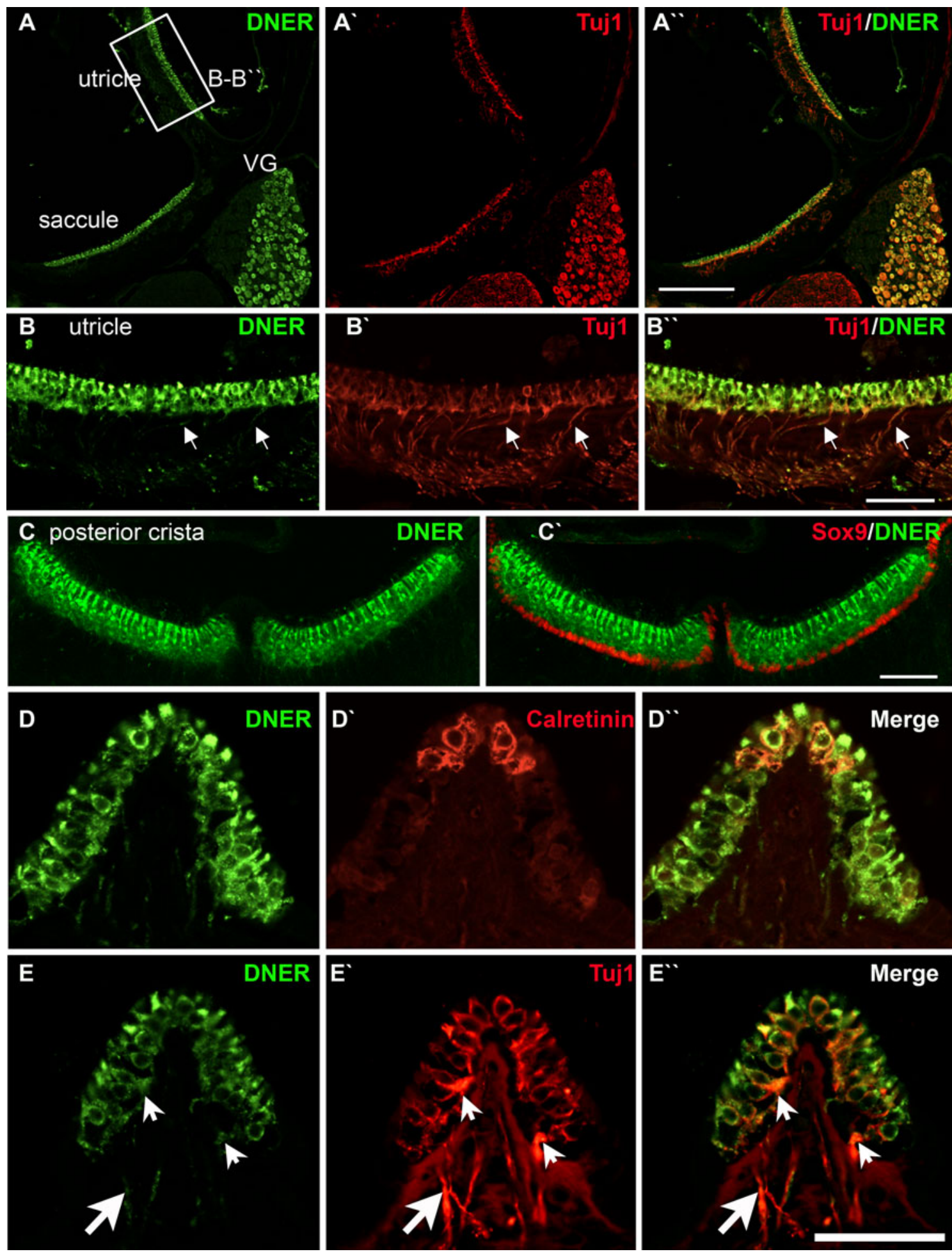

We found that DNER is expressed in developing auditory hair cells at very low levels during embryonic and early neonatal development, and becomes expressed at progressively stronger levels during the first postnatal week. DNER was not detectable in cochlear hair cells at E15.5 (Fig. 3A'"'), but a low level of DNER immunoreactivity was present in hair cells at E17.5 and overlapped with Math1-GFP (Fig. 3B'-B'"', arrowheads). Similarly, weak DNER immunolabeling was present in hair cells at P2, above the more intensely labeled

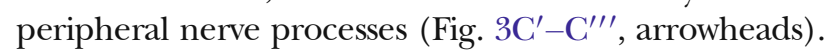
DNER immunoreactivity in auditory hair cells becomes 
FIG. 4. DNER is expressed in adult vestibular hair cells, peripheral nerve endings, and vestibular ganglion cell bodies. A-A" A low magnification view of a section through the vestibular part of the inner ear containing utricle, saccule, and vestibular ganglion (VG) was immunolabeled with DNER (green $\mathbf{A}, \mathbf{A}^{\prime \prime}$ ) and Tuj1 (red $\mathbf{A}^{\prime}, \mathbf{A}^{\prime \prime}$ ). In this view strong DNER expression can be seen in the hair cells of the utricle and crista as well as the cell bodies of the vestibular ganglia, while Tuj1 labels the vestibular ganglion cells and all of their afferent fibers in the vestibular organs. B-B" A high magnification view of the utricle section in the boxed region of $\mathbf{A}$, showing DNER (B), Tuj1 ( $\left.\mathbf{B}^{\prime}\right)$ and the two channels merged ( $\left.\mathbf{B}^{\prime \prime}\right)$. DNER expression is strong in hair cells and can also be seen at lower levels in the Tuj1positive afferent fibers (small arrows point to two examples) and their endings beneath the hair cells. $\mathbf{C}-\mathbf{C}^{\prime}$ An optical section showing a longitudinal view of a posterior crista labeled with DNER $\left(\mathbf{C}-\mathbf{C}^{\prime}\right)$ and the supporting cell nuclear marker Sox9 $\left(\mathbf{C}^{\prime}\right)$. Similar to the expression in the macular organs, anti-DNER labeling is strong in the hair cells and less intense in the underlying neurites. DNER is not expressed in supporting cells. D-D" A transverse section of a crista double labeled with DNER $\left(\mathbf{D}, \mathbf{D}^{\prime \prime}\right)$ and the pure calyceal afferent marker calretinin shows that DNER is expressed in the type I hair cells at the apices and is present in the calyceal nerve ending but does not completely overlap with calretinin. E-E" A similar section to D-D" double labeled with DNER and Tuj1 shows that DNER is expressed in some of the afferent neurites (large arrow) and terminals below the hair cells (arrowheads) but is not colocalized with Tuj1 throughout the flask-shaped calyceal endings that envelope many of the hair cells. Scale bar in $\mathbf{A}^{\prime \prime}=200 \mu \mathrm{m}$. Scale bars in $\mathbf{B}^{\prime \prime}, \mathbf{C}^{\prime}$, and $\mathbf{E}^{\prime \prime}=$ $50 \mu \mathrm{m}$.

markedly more intense at $\mathrm{P} 4$, particularly in outer hair cells, which are labeled with anti-DNER only slightly less intensely than the nearby peripheral neurites (Fig. 3D'$\mathrm{D}^{\prime \prime \prime}$, arrowheads). By P7, DNER is expressed strongly in outer hair cells and has reached a moderate level in

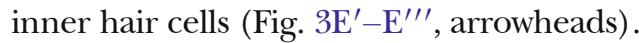

\section{DNER is expressed in adult vestibular hair cells and vestibular ganglion neurons}

We performed immunolabeling experiments in the adult mouse vestibule and found that DNER is expressed in hair cells in all five vestibular organs and in vestibular ganglion neurons (Fig. 4). In sections at low magnification, DNER immunolabeling was visible in all hair cells in the utricle and saccule and colocalized with Tuj1 in all of the vestibular ganglion neuron cell bodies (Fig. $4 \mathrm{~A}-\mathrm{A}^{\prime \prime}$ ). At higher magnification, anti-DNER sparsely labeled afferent neurite fibers and was abundant in nerve terminals below utricular hair cells (Fig. 4B-B" ). DNER labeling in vestibular hair cells was similar to that observed in auditory hair cells; it was strong but somewhat punctate, excluded from the nucleus, enriched in the apical portion of hair cells but very weak or not present in hair cell bundles. To confirm that DNER expression in nerve terminals below hair cells was not present in supporting cells, we doublelabeled vestibular organs with anti-DNER and anti-Sox9 (Fig. $4 \mathrm{C}-\mathrm{C}^{\prime}$ ). Sox9 has been shown to be expressed in auditory and vestibular supporting cells during development (Mak et al. 2009), and we find that Sox9 labels nuclei of supporting cells and mesenchymal cells, but not hair cells, in the adult. DNER expression did not overlap with Sox9, as seen in a longitudinal optical section through a posterior crista whole-mount immunolabeled for DNER and Sox9 (Fig. 4C- $\mathrm{C}^{\prime}$ ). To determine the localization of DNER in nerve terminals, we colabeled sections with anti-calretinin, which specifically labels all pure calyceal afferent terminals (Desmadryl and Dechesne 1992, Dechesne et al. 1994, Li et al. 2008a, b), or anti-Tuj1, which labels all afferent neurites and terminals (Li et al. 2008a, b). Transverse sections through cristae double labeled with anti-DNER and anti-calretinin displayed partially overlapping expression patterns (Fig. 4D-D"'). DNER was found within the lower portions of calretininlabeled calyceal endings but did not label the whole calyx (Fig. 4D"'). A similar pattern was observed in cristae sections double labeled with anti-DNER and anti-Tuj1 (Fig. 4E-E' ${ }^{\prime \prime}$. DNER expression was found in hair cells and underlying nerve terminals (arrowheads) and some fibers (arrows), but was not localized to the flask-shaped calyceal endings.

DNER is expressed in vestibular hair cells and peripheral neurites during embryonic and postnatal development

We next carried out a series of developmental studies of DNER expression in the hair cells and neurons of vestibular epithelia, and here we show examples of DNER expression in cristae at E15.5, P1, and P5 (Fig. 5). In contrast to the postnatal onset of DNER in auditory hair cells, we found that DNER is expressed in vestibular hair cells during embryonic development, as early as E15.5 (Fig. 5A). DNER was also colocalized with Tuj1 in peripheral afferent nerve processes underlying the vestibular epithelia (Fig. 5A, inset), at this age. Similarly, in the neonatal crista, DNER was expressed in hair cells and weakly expressed in peripheral neurites (Fig. 5B). To confirm expression of DNER in vestibular hair cells we probed P5 crista sections with DNER antisense probe and found signal specifically in the hair cell layer of the sensory epithelium (Fig. 5C). Overall, DNER immunoreactivity in developing vestibular epithelia was similar to that of adult vestibular organs but appeared slightly less intense during embryonic development.

\section{DNER-/- mice exhibit normal organ of Corti morphology and patterns of supporting cell maturation}

Earlier studies have shown that DNER is expressed in neurons and is involved in regulating maturation of 

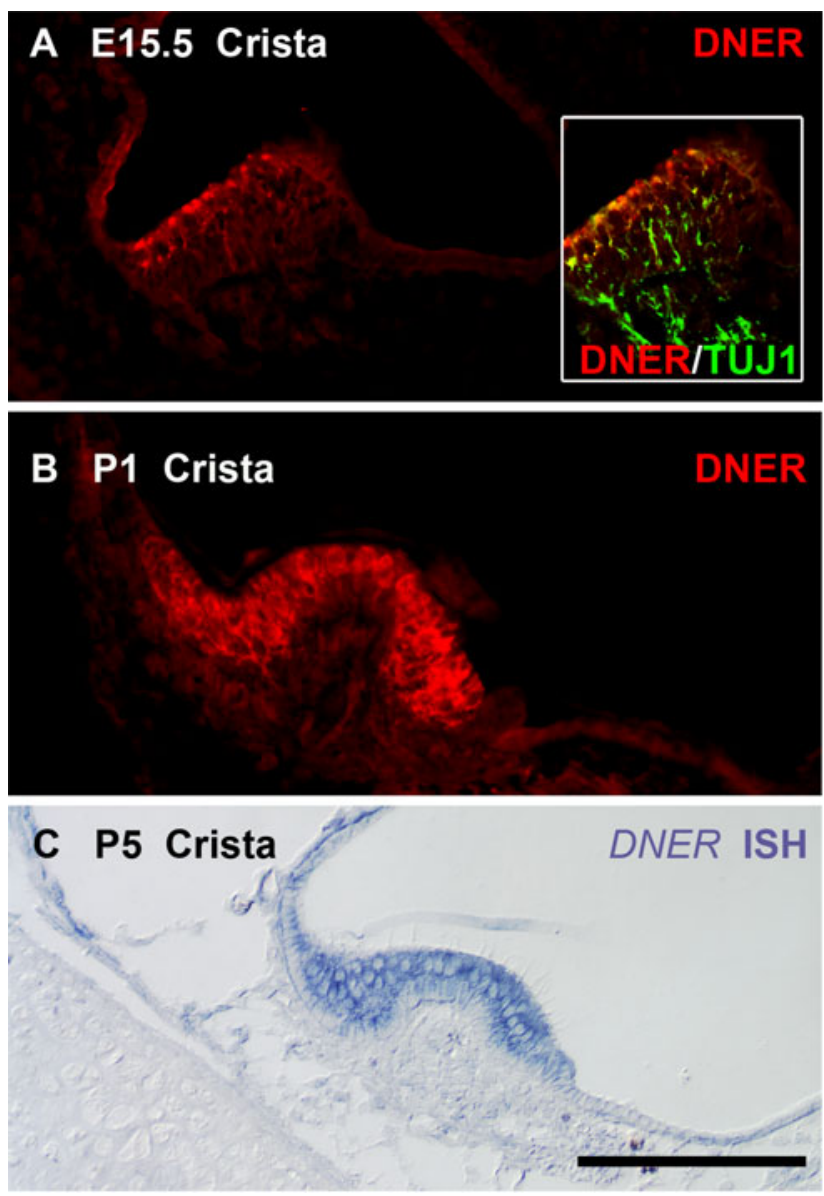

FIG. 5. DNER is expressed in neurites and hair cells of vestibular epithelia during embryonic and neonatal development, as shown in transverse sections of cristae. A DNER immunolabeling is detectable at moderate levels in vestibular hair cells and neurites as early as E15.5, inset shows colabeling of neurons with Tuj1 (green). B At P1, DNER expression is strong in vestibular hair cells and is also found in neurites. C In situ hybridization for DNER (b/ue) message in P5 crista confirms that DNER is produced in vestibular hair cells. Scale bar= $100 \mu \mathrm{m}$.

glia in the CNS, presumably through intercellular Notch signaling: DNER-/- mice have defective maturation of Bergman glia, with reductions in GLAST expression and altered morphology (Eiraku et al. 2005, Tohgo et al. 2006). In order to test whether DNER plays a similar role in glial and supporting cell maturation in the cochlea we examined inner ears from adult $D N E R-/-$ mice and wild-type littermate controls. The organs of Corti of $D N E R-/-$ mice lack DNER immunoreactivity (Fig. $6 \mathrm{~B}^{\prime}-\mathrm{B}^{\prime \prime}$ ), but otherwise exhibit normal morphology and expression patterns of markers of hair cells, neurons, and mature supporting cells (Fig. 6). The intermediate filament, GFAP, is expressed in cochlear supporting cells during postnatal maturation and in adult mice (Rio et al. 2002). Consistent with Rio et al., we found that GFAP is expressed in inner phalangeal cells, pillar cells, and Deiters' cells in the normal adult cochlea
(Fig. 6A-A $\mathrm{A}^{\prime \prime}$ ). Expression of GFAP appeared normal in DNER-/- mice, which completely lacked DNER immunoreactivity (Fig. 6B-B). To evaluate the structure and morphology of the organ of Corti in mutant animals we immunolabeled hair cells with myosinVIIa and labeled filamentous actin with conjugated phalloidin (Fig. 6C-D $\mathrm{D}^{\prime \prime}$ ). We did not detect any abnormalities in the levels or pattern of phalloidin labeling in pillars or Deiters' cells in mutant animals, and cellular morphology of these cells appeared normal (Fig. 6D-D'f). Previous studies have reported GLAST expression in inner phalangeal supporting cells (Li et al. 1994, Furness and Lehre 1997, Jin et al. 2003), which increases progressively during the second postnatal week, and reaches adult levels after two postnatal weeks in the mouse (Jin et al. 2003). Although the developmental time course of GLAST expression correlates with DNER expression, we did not find any change in GLAST expression in the DNER-/- mice.

In addition to analyzing the above markers, we also labeled DNER-/- and control cochlear sections with antibodies against hair cell and neuronal markers myosinVI, synaptophysin, and Tuj1, which resulted in the similar patterns as those shown in Fig. 1 and indicated no gross abnormalities in DNER-/- cochleae (data not shown). To further confirm that supporting cells were unaffected in mutant mice we labeled with antibodies to Sox2, S100A1, Jag1, and P27kip1 and found that these supporting cell markers also stained with normal patterns in $D N E R-/-$ cochleae (data not shown).

Spiral ganglia of adult DNER-/- mice exhibit normal neuronal morphology and patterns of glia and myelin staining

We double-labeled spiral ganglia of adult DNER-/and control mice with anti-NF-M, to label spiral ganglion neurons, and anti-GLAST or anti-CNPase, to evaluate glial maturation and myelination (Fig. 7). Spiral ganglion neuron morphology and NF-M immunoreactivity appeared normal in DNER-/mice. Since $D N E R-/-$ mice exhibit impaired glial maturation and GLAST expression in the cerebellum, we looked at GLAST immunoreactivity in glia of the spiral ganglia. Previous studies have reported GLAST expression in spiral ganglion satellite cells surrounding type I spiral ganglion neurons (Li et al. 1994, Furness and Lehre 1997, Jin et al. 2003). We double-labeled spiral ganglion sections for GLAST and NF-M and found that patterns of GLAST immunolabeling in satellite cells and NF-M in spiral ganglion cell somata and neurites were similar in wild-type and $D N E R-/-$ cochleae (Fig. 7A-A' and 

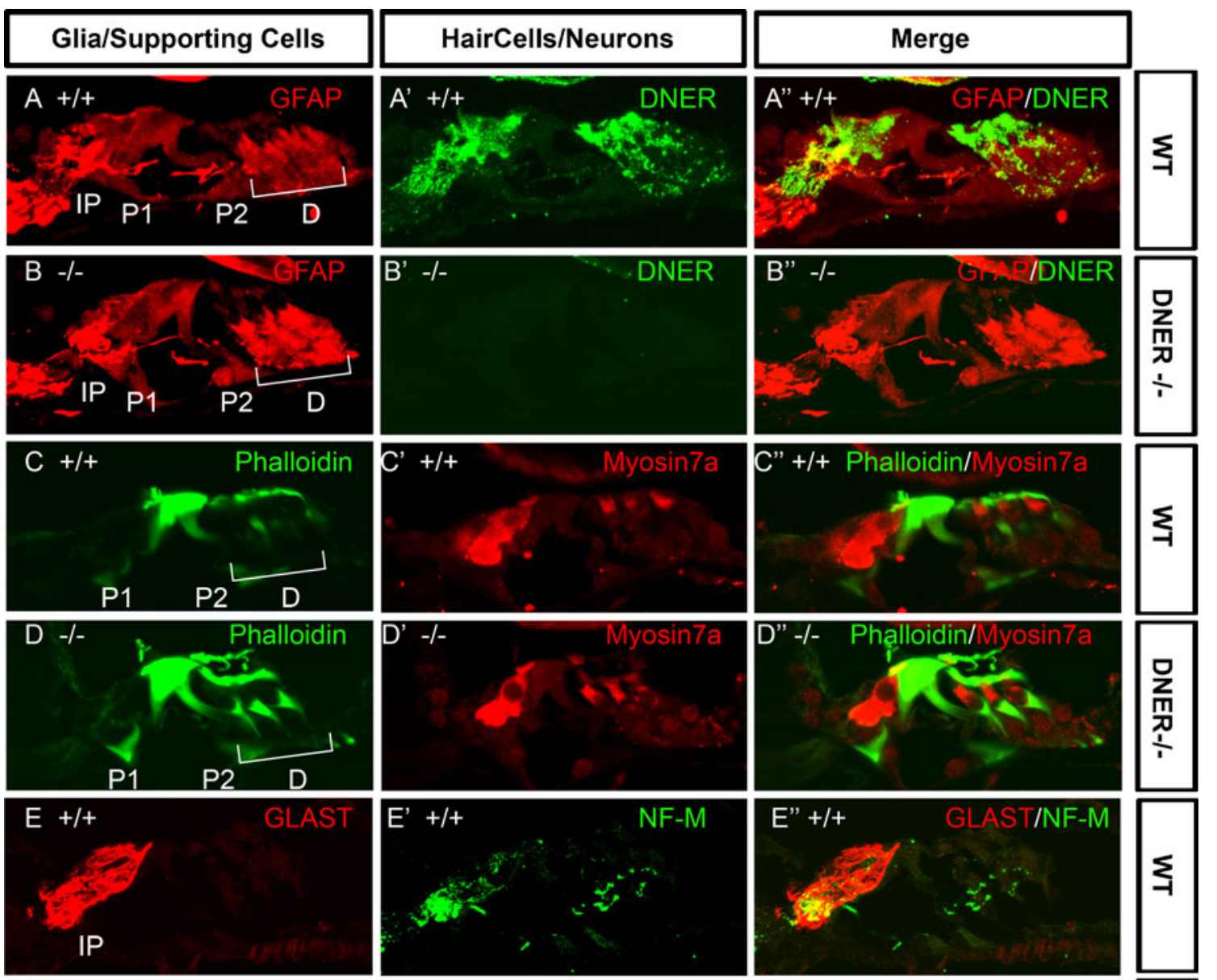
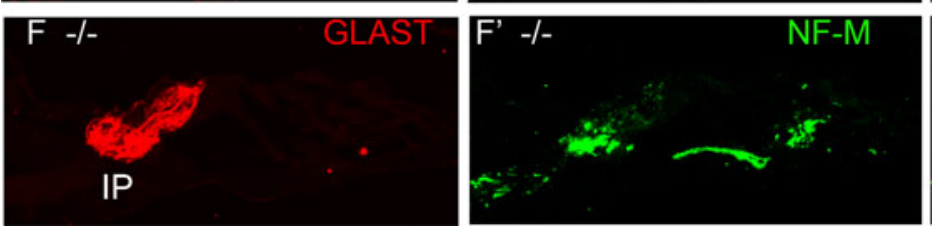

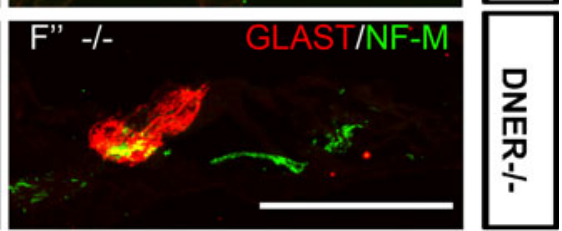

FIG. 6. Organs of Corti of DNER-/- mice lack DNER immunoreactivity but exhibit normal morphology and expression patterns of hair cell and supporting cell markers. A-B" Wild-type $\left(\mathbf{A}-\mathbf{A}^{\prime \prime}\right)$ and DNER-/- (B-B") cochlea sections were double labeled for DNER (green) and GFAP (red), a marker of glia and mature supporting cells. DNER immunolabeling is absent in DNER-/- animals $\left(\mathbf{B}^{\prime}-\mathbf{b}^{\prime \prime}\right)$, but normal expression of GFAP was observed in inner phalangeal cells (IP), pillar cells ( $P 1$ and $P 2)$, and Deiters' cells (D, bracket). C-D" In a

$\left.\mathrm{B}-\mathrm{B}^{\prime \prime}\right)$. To label myelin and glial cells in the spiral ganglia we used a monoclonal antibody to CNPase (RIP antigen), which has been commonly used to label myelin, oligodendrocytes, and peripheral ensheathing glia (Watanabe et al. 2006, Toma et al. 2007). We found that anti-CNPase provided strong labeling of myelin surrounding the somata and ensheathing the processes of type I spiral ganglion cells as well as myelin ensheathing efferent fibers in the intraganglionic spiral bundle (Fig. 7C$\left.\mathrm{C}^{\prime \prime}\right)$. We double labeled $D N E R-/-$ and wild-type spiral ganglia with CNPase and NF-M and found similar set of sections from wild-type $\left(\mathbf{C}-\mathbf{C}^{\prime \prime}\right)$ and DNER null (D-D $\left.\mathbf{D}^{\prime \prime}\right)$ mice, F-actin (in pillar cells, Deiters' cells, and hair cell bundles) was labeled with conjugated phalloidin (green) and hair cells were labeled with anti-myosinVIla (red). E-F" Similarly, patterns of GLAST immunolabeling ( $r e d$ ) in the membranes of inner phalangeal cells and Neurofilament-M (green) in peripheral neurites were similar in wild-type $\left(\mathbf{E}-\mathbf{E}^{\prime \prime}\right)$ and DNER-/- $\left(\mathbf{F}-\mathbf{F}^{\prime \prime}\right)$ cochleae. Scale bar=100 $\mu \mathrm{m}$.

that mutants did not display any abnormalities in myelin patterns or morphology.

\section{DISCUSSION}

Earlier studies have described DNER expression in developing and adult CNS neurons (Eiraku et al. 2002, Eiraku et al. 2005). Here we describe the expression pattern of DNER in developing and adult neurons and hair cells in the inner ear. In the CNS, DNER expression was shown to actively promote 

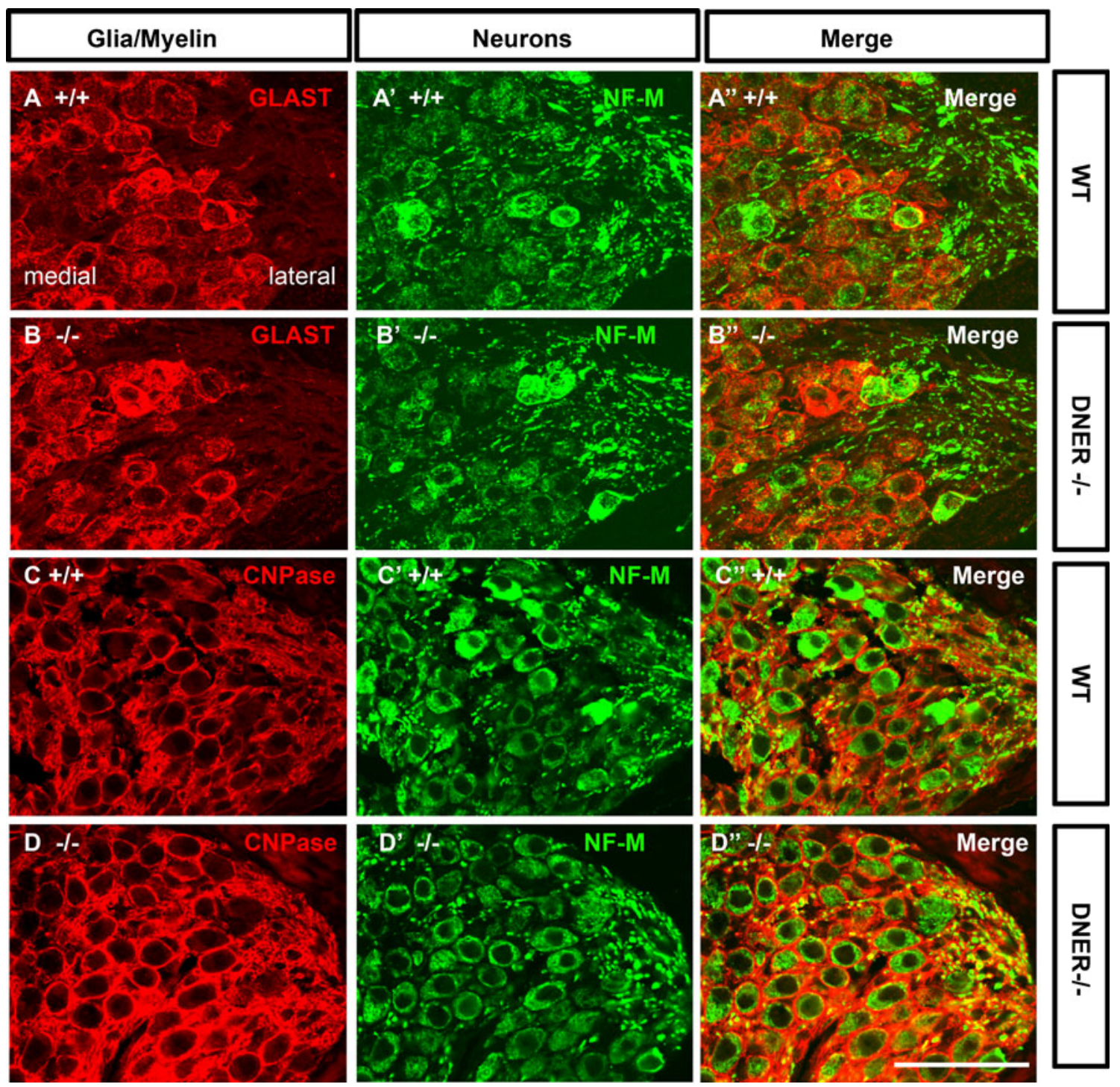

FIG. 7. Spiral ganglia of $D N E R-/-$ mice exhibit normal neuronal and glial morphology and myelination patterns. A-B" Sections through spiral ganglia of wild-type $\left(\mathbf{A}-\mathbf{A}^{\prime \prime}\right)$ and DNER-/- (B-B") mice were double labeled with the glial marker GLAST (red) and NF-
$\mathrm{M}$ (green) which labels all spiral ganglion cell bodies and processes C-D" Similar wild-type $\left(\mathbf{C}-\mathbf{C}^{\prime \prime}\right)$ and DNER-/- (D-D") sections were immunostained with CNPase (red) to label myelin as well as NF-M (green). Scale bar=100 $\mu \mathrm{m}$. morphological and functional maturation of glia through intercellular activation of Notch signaling (Eiraku et al. 2005, Saito and Takeshima 2006, Tohgo et al. 2006). In the auditory sensory epithelia, supporting cells of the organ of Corti have features similar to glia. Inner phalangeal cells ensheath the inner hair cell synapse and express the glutamate transporter GLAST (Li et al. 1994, Furness and Lehre 1997, Ottersen et al. 1998, Furness and Lawton 2003, Jin et al. 2003), which has been shown to mediate glutamate uptake at inner hair cell afferent synapses (Glowatzki et al. 2006) and play a role in preventing degeneration of hair cells caused by noise damage or aminoglycoside toxicity (Hakuba et al. 2000, Shimizu et al. 2005). Cochlear supporting cells have been shown to exhibit GFAP expression and promoter activity (Rio et al. 2002, Stone et al. 2005), which is also characteristic of CNS glia. Based on these observations, we reasoned that DNER could function to promote maturation of glia and supporting cells in the inner ear and that $D N E R-/-$ mice may exhibit defects in glial and supporting cell morphology and/or protein expression. Our finding that adult $D N E R-/-$ mice display apparently normal supporting cells and glia in the cochlea suggests that DNER is not required for maturation of these cell types through Notch signaling as it is in the CNS. Additionally, although DNER-/mice have no abnormalities in glial or supporting cell morphology or protein expression we cannot completely rule out the possibility of a defect, without 
physiological studies of auditory and vestibular function, which were not feasible for this study. Furthermore, although DNER-/- mice show slightly impaired cerebellar function and motor discoordination on a rota-rod test (Tohgo et al. 2006) we did not observe any circling or head turning behaviors or balance defects indicative of vestibular disorder.

Although DNER has been shown to regulate the differentiation of glial cells in the CNS, our results indicate that it is not required for this function in the inner ear. It is possible that some other Notch ligand plays a similar role in the developing inner ear epithelia and that DNER is therefore redundant. Previous studies have shown that many Notch ligands are expressed in the developing inner ear, including Dll1, Dll3, Jag1, and Jag2, and that Notch ligands have redundant actions in embryonic development (Lewis et al. 1998, Lanford et al. 1999, Morrison et al. 1999, Kiernan et al. 2005, Hartman et al. 2007). At least one of these ligands, Jag1, is present in the postnatal cochlea and even into adulthood (Morrison et al. 1999, Oesterle et al. 2008) and could thus serve to maintain active Notch in the maturing support cells. It is also possible that the function of DNER on glial maturation could be compensated for with a different signaling pathway. Doetzlhofer et al (2009) recently reported that pillar cell maturation requires Hey2, which may be regulated by FGF signaling, rather than or in addition to Notch; this is a good example of how downstream targets of the Notch pathway can also be regulated by other signaling molecules. It is also possible that Notch signaling is not required for supporting cell maturation, as it appears to be for glia in the CNS. Several lines of evidence, including localization of activated Notch (Murata et al. 2006) and analysis of Hes5-GFP reporter mice (Hartman et al. 2009) indicate that Notch signaling may be very low or absent in the support cells after the first few postnatal days.

Our results, together with other recent reports, therefore lead us to conclude that support cells appear not to require DNER or canonical Notch signaling during the later stages of their maturation and for maintenance of their phenotype in the mature inner ear sensory epithelia. Moreover, the glia and neurons of the vestibular and cochlear ganglia are not grossly affected by loss of DNER. Nevertheless, the robust expression of this molecule suggests that there may be other roles for DNER that eluded our analysis. Interestingly, DNER was recently shown to be actively endocytosed by a protein tyrosine phosphatase and inhibit neurite outgrowth in Neuro2A cells (Fukazawa et al. 2008) and earlier studies have shown that Notch plays a role in regulating neurite extension and growth (Artavanis-Tsakonas et al. 1999, Berezovska et al. 1999, Redmond et al. 2000,
Redmond and Ghosh 2001). Thus, it will be interesting for future studies to explore other possible roles of DNER in the inner ear, such as in cochlear and vestibular ganglion cell neuritogenesis.

\section{ACKNOWLEDGEMENTS}

This research is supported by the following grants: NRSA \#T32 HD007183-26A1 to B.H.H., NIH/NIDCD grant DC005953 to O.B-McD., NIH/NEI RO1 grant EY13475 to T.A.R. Dr. Hiroshi Takeshima and Dr. Hirohito Miura generously provided DNER knockout mice. Math1-GFP mice were a gift of Dr. Jane Johnson. Myosin7a antibody was a gift of Dr. Stefan Heller. Dr. Susan Dowling and Linda Robinson generously helped with animal care and use. Members of the Reh and Bermingham-McDonogh labs provided support and advice.

\section{REFERENCES}

ArtaVanis-Tsakonas S, Rand MD, Lake RJ (1999) Notch signaling: cell fate control and signal integration in development. Science 284:770-776

Berezovska O, Mclean P, Knowles R, Frosh M, Lu FM, Lux SE, Hyman BT (1999) Notch1 inhibits neurite outgrowth in postmitotic primary neurons. Neuroscience 93:433-439

Brooker R, Hozumi K, Lewis J (2006) Notch ligands with contrasting functions: Jagged1 and Delta1 in the mouse inner ear. Development 133:1277-1286

Corrales CE, Pan L, Li H, Liberman MC, Heller S, Edge aS (2006) Engraftment and differentiation of embryonic stem cell-derived neural progenitor cells in the cochlear nerve trunk: growth of processes into the organ of Corti. J Neurobiol 66:1489-1500

Counter SA, Canlon B, Borg E, Aldskogius H (1997) Pattern of synaptophysin immunoreactivity in the efferent nerve terminals of the guinea pig cochlea. Neurosci Lett 222:199-203

Dechesne CJ, Winsky L, Kim HN, Goping G, Vu TD, Wenthold RJ, JAсовоwITZ DM (1991) Identification and ultrastructural localization of a calretinin-like calcium-binding protein (protein 10) in the guinea pig and rat inner ear. Brain Res 560:139-148

Dechesne CJ, Rabejac D, Desmadryl G (1994) Development of calretinin immunoreactivity in the mouse inner ear. J Comp Neurol 346:517-529

Desmadryl G, Dechesne CJ (1992) Calretinin immunoreactivity in chinchilla and guinea pig vestibular end organs characterizes the calyx unit subpopulation. Exp Brain Res 89:105-108

Doetzlhofer A, Basch ML, Ohyama T, Gessler M, Groves AK, Segil N (2009) Hey2 regulation by FGF provides a Notch-independent mechanism for maintaining pillar cell fate in the organ of Corti. Dev Cell 16:58-69

Eiraku M, Hirata Y, Takeshima H, Hirano T, Kengaku M (2002) Delta/notch-like epidermal growth factor (EGF)-related receptor, a novel EGF-like repeat-containing protein targeted to dendrites of developing and adult central nervous system neurons. J Biol Chem 277:25400-25407

Eiraku M, Tohgo A, Ono K, Kaneko M, Fujishima K, Hirano T, KENGAKU M (2005) DNER acts as a neuron-specific Notch ligand during Bergmann glial development. Nat Neurosci 8:873-880

Fukazawa N, Yokoyama S, Eiraku M, Kengaku M, Maeda N (2008) Receptor type protein tyrosine phosphatase zeta-pleiotrophin 
signaling controls endocytic trafficking of DNER that regulates neuritogenesis. Mol Cell Biol 28:4494-4506

Furness DN, LaWton DM (2003) Comparative distribution of glutamate transporters and receptors in relation to afferent innervation density in the mammalian cochlea. J Neurosci 23:11296-11304

FurNess DN, LeHRE KP (1997) Immunocytochemical localization of a high-affinity glutamate-aspartate transporter, GLAST, in the rat and guinea-pig cochlea. Eur J NeuroSci 9:1961-1969

Gil-Loyzaga P, Pujol R (1988) Synaptophysin in the developing cochlea. Int J Dev Neurosci 6:155-160

Glowatzki E, Cheng N, Hiel H, Yi E, Tanaka K, Ellis-Davies GC, Rothstein JD, Bergles DE (2006) The glutamate-aspartate transporter GLAST mediates glutamate uptake at inner hair cell afferent synapses in the mammalian cochlea. J Neurosci 26:7659-7664

Hafid A (1998) Peripherin-like immunoreactivity in type II spiral ganglion cell body and projections. Brain Res 805:181-190

Hafidi A, Despres G, Romand R (1993) Ontogenesis of type II spiral ganglion neurons during development: peripherin immunohistochemistry. Int J Dev Neurosci 11:507-512

Hakuba N, Koga K, Gyo K, Usami SI, Tanaka K (2000) Exacerbation of noise-induced hearing loss in mice lacking the glutamate transporter GLAST. J Neurosci 20:8750-8753

Hartman BH, Hayashi T, Nelson BR, Bermingham-McDonogh O, Reh TA (2007) Dl13 is expressed in developing hair cells in the mammalian cochlea. Dev Dyn 236:2875-2883

Hartman BH, Basak O, Nelson BR, Taylor V, Bermingham-McDonogh O, ReH TA (2009) Hes5 expression in the postnatal and adult mouse inner ear and the drug-damaged cochlea. J Assoc Res Otolaryngol 10(3):321-340

Hayashi T, Kokubo H, Hartman BH, Ray CA, Reh ta, BerminghamMcDonogh O (2008) Hesr1 and Hesr2 may act as early effectors of Notch signaling in the developing cochlea. Dev Biol 316:8799

Hayashi T, Cunningham D, Bermingham-McDonogh O (2007) Loss of Fgfr3 leads to excess hair cell development in the mouse organ of Corti. Dev Dyn 236:525-533

Jin ZH, Kikuchi T, Tanaka K, Kobayashi T (2003) Expression of glutamate transporter GLAST in the developing mouse cochlea. Tohoku J Exp Med 200:137-144

Kauffman MH (1992) The atlas of mouse development. Elsevier Academic, London, p 525

Kiernan AE, Cordes R, Kopan R, Gossler A, Gridley T (2005) The Notch ligands DLL1 and JAG2 act synergistically to regulate hair cell development in the mammalian inner ear. Development 132:4353-4362

Kiernan AE, Xu J, Gridley T (2006) The notch ligand JAG1 Is required for sensory progenitor development in the mammalian inner ear. PLoS Genet 2:e4

Knipper M, Zimmermann U, Rohbock K, Kopschall I, ZenNer HP (1995) Synaptophysin and GAP-43 proteins in efferent fibers of the inner ear during postnatal development. Brain Res Dev Brain Res 89:73-86

Koo JW, Homanics GE, Balaban CD (2002) Hypoplasia of spiral and Scarpa's ganglion cells in GABA(A) receptor beta(3) subunit knockout mice. Hear Res 167:71-80

Lallemend F, Vandenbosch R, Hadjab S, Bodson M, Breuskin I, Moonen G, Lefebvre PP, Malgrange B (2007) New insights into peripherin expression in cochlear neurons. Neuroscience 150:212-222

Lanford PJ, Lan Y, Jiang R, Lindsell C, Weinmaster G, Gridley T, KeLLEY MW (1999) Notch signalling pathway mediates hair cell development in mammalian cochlea. Nat Genet 21:289292
Lewis AK, Frantz GD, Carpenter DA, de Sauvage FJ, Gao WQ (1998) Distinct expression patterns of notch family receptors and ligands during development of the mammalian inner ear. Mech Dev 78:159-163

Li HS, Niedzielski AS, Beisel KW, Hiel H, Wenthold RJ, Morley BJ (1994) Identification of a glutamate/aspartate transporter in the rat cochlea. Hear Res 78:235-42

Li A, Xue J, Peterson EH (2008a) Architecture of the mouse utricle: macular organization and hair bundle heights. J Neurophysiol 99:718-733

Li S, Mark S, Radde-Gallwitz K, Schlisner R, Chin MT, Chen P (2008b) Hey2 functions in parallel with Hes1 and Hes5 for mammalian auditory sensory organ development. BMC Dev Biol 8:20

Mak AC, Szeto IY, Fritzsch B, Cheah KS (2009) Differential and overlapping expression pattern of SOX2 and SOX9 in inner ear development. Gene Expr Patterns 9(6):444-453

Morrison A, Hodgetts C, Gossler A, HrabedeAngelis M, Lewis J (1999) Expression of Delta1 and Serrate1 (Jagged1) in the mouse inner ear. Mech Dev 84:169-172

Murata J, Tokunaga A, Okano H, Kubo T (2006) Mapping of notch activation during cochlear development in mice: implications for determination of prosensory domain and cell fate diversification. J Comp Neurol 497:502-518

Nelson BR, Sadhu M, Kasemeier JC, Anderson LW, Lefcort F (2004) Identification of genes regulating sensory neuron genesis and differentiation in the avian dorsal root ganglia. Dev Dyn 229:618-629

Nishizumi H, Komirama T, Mirabayashi T, Sakano S, Sakano H (2002) BET, a novel neuronal transmembrane protein with multiple EGF-like motifs. NeuroReport 13:909-915

Oesterle EC, Campbell S, Taylor RR, Forge A, Hume CR (2008) Sox2 and JAGGED1 expression in normal and drug-damaged adult mouse inner ear. J Assoc Res Otolaryngol 9:65-89

Ottersen OP, Takumi Y, Matsubara A, Landsend AS, LaAke JH, Usami $\mathrm{S}$ (1998) Molecular organization of a type of peripheral glutamate synapse: the afferent synapses of hair cells in the inner ear. Prog Neurobiol 54:127-148

Redmond L, GHosh A (2001) The role of Notch and Rho GTPase signaling in the control of dendritic development. Curr Opin Neurobiol 11:111-117

Redmond L, Oh SR, Hicks C, Weinmaster G, Ghosh A (2000) Nuclear Notch1 signaling and the regulation of dendritic development. Nat Neurosci 3:30-40

Rio C, Dikkes P, Liberman MC, Corfas G (2002) Glial fibrillary acidic protein expression and promoter activity in the inner ear of developing and adult mice. J Comp Neurol 442:156-162

SAITO SY, TAKESHIMA H (2006) DNER as key molecule for cerebellar maturation. Cerebellum 5:227-231

Shimizu Y, Hakuba N, Hyodo J, Taniguchi M, Gro K (2005) Kanamycin ototoxicity in glutamate transporter knockout mice. Neurosci Lett 380:243-246

Stone IM, Lurie DI, Kelley MW, Poulsen DJ (2005) Adenoassociated virus-mediated gene transfer to hair cells and support cells of the murine cochlea. Mol Ther 11:843-848

Takebayashi S, Yamamoto N, Yabe D, Fukuda H, Kojima K, Ito J, Honjo $\mathrm{T}$ (2007) Multiple roles of Notch signaling in cochlear development. Dev Biol 307(1):165-178

Tohgo A, Eiraku M, Mifazaki T, Miura E, Kawaguchi Sy, Nishi M, Watanabe M, Hirano T, Kengaku M, Takeshima H (2006) Impaired cerebellar functions in mutant mice lacking DNER. Mol Cell Neurosci 31:326-333

Toma JS, McPhail LT, Ramer MS (2007) Differential RIP antigen (CNPase) expression in peripheral ensheathing glia. Brain Res 1137:1-10

WARR WB, Guinan JJ JR (1979) Efferent innervation of the organ of corti: two separate systems. Brain Res 173:152-155 
Watanabe M, Sakurai Y, Ichinose T, Aikawa Y, Kotani M, Itoh K (2006) Monoclonal antibody Rip specifically recognizes 2', 3'-cyclic nucleotide 3 '-phosphodiesterase in oligodendrocytes. J Neurosci Res 84:525-533

Zheng JL, Shou J, Guillemot F, Kageyama R, Gao WQ (2000) Hes1 is a negative regulator of inner ear hair cell differentiation. Development 127:4551-4560
Zine A, Van De Water TR, de Ribaupierre F (2000) Notch signaling regulates the pattern of auditory hair cell differentiation in mammals. Development 127:3373-3383

Zine A, Aubert A, Qiu J, Therianos S, Guillemot F, Kageyama R, de RibaUPIERRE F (2001) Hes1 and Hes5 activities are required for the normal development of the hair cells in the mammalian inner ear. J Neurosci 21:4712-4720 